\title{
The Comparison of Behavior Patterns between Chinese and South Korean Employees Based on Cultural Dimensions
}

\author{
Nanshun JIN ${ }^{1, a^{*}}$, Liyao PAN ${ }^{1, b}$ \\ ${ }^{1}$ College of Economics and Management, Dalian University, P. R. China, 116622 \\ anancykim@163.com \\ bliyao.pan@hotmail.com
}

Key words: Behavior pattern; Hofstede 's cultural dimensions; Value orientation; Employees

\begin{abstract}
In this paper we chose Hofstede's cultural dimensions as the research tool to investigate the differences in value orientations between Chinese and South Korean employees in Sino-South Korean joint ventures. Further, we discussed the differences in behavior patterns between the two sides on the basis of the Hofstede's research findings on the relationships between value orientations and behavior patterns. Based on the findings on the differences in behavior patterns between the two sides, we made some suggestions to address the problems in cross cultural management, which refer to implementation capacity, sense of mission towards the enterprise, gender composition of the management team, and enterprise regulations.
\end{abstract}

\section{Introduction}

Culture is viewed exclusively as a cause of individual behavior from numerous review cross-cultural studies [1]. The influence of national culture on an individual's value was verified by Brockner et al. (2010)'s study regarding culture and fairness[2]. Also, Fischer et al. (2014) found the structure similarity in cultural values between individual and country-levels[3]. The Hofstede's cultural dimensions is so far the most influential work in the field of cross-cultural study[4] due to the cross-national generalizability of this cultural measure, as demonstrated by high reliability and validity across different samples in Yoo et al. (2011)'s study[5].

Chinese and South Korean employees have different value orientations because of the influence of historical and geographical conditions. The different behavior patterns, resulted from different value orientations, have positive and negative effects on interaction with each other. As a result, the academic circles have paid much attention to the way to make employees who have different value orientations get on well.

Introduction to Hofstede's cultural dimensions. Hofstede put forward some value orientations widely possessed by cultural groups in the early 1970s, which refer to power distance, individualism-collectivism, masculinity-femininity, and uncertainty avoidance[6].

Among these value orientations, power distance reflects the extent to which social members accept unequal power distribution. Regarding the relationship between this value orientation and resulting behavior, Hofstede believes that the more inclination of power distance a society has, the more dependence social members have on the elders. According to his research findings, employees with more inclination of power distance are more inclined to carry out instructions from superiors[7].Individualism-collectivism refers to relationships among people. In individualistic societies, people are expected to stand for themselves. In collectivism society, people are expected to act as members of cohesive group. Regarding the relationship between this value orientation and resulting behavior, Hofstede believes that the more inclination of collectivism a society has, the more loyalty social members have to their own groups. According to his research findings, employees with more inclination of collectivism are more inclined to have sense of mission towards the enterprises[7].

Masculinity-femininity involves two aspects: quality of life and masculinity. Quality of life focuses on how a society emphasizes the importance of deep communication. Concerning the 
relationship between this value orientation and resulting behavior, Hofstede believes that the more inclination of life quality a society has, the more concern social members show to others. According to his research findings, employees with more inclination of life quality are more likely to believe that the enterprise leaders should pay much attention to employee welfare. Masculinity focuses on how a society emphasizes the importance of differences between gender roles. The more inclination of masculinity a society has, the more inclined social members are to support the differences between social gender roles. It is therefore clear that employees with more inclination of masculinity are more likely to believe that gender should play an important role in job descriptions [6] [7].

Uncertainty avoidance reflects the extent to which social members are likely to deal with anxiety by minimizing uncertainty. With regards to the relationship between this value orientation and resulting behavior, Hofstede believes that the more inclination of uncertainty avoidance a society has, the more dependence social members have on rules. According to his research findings, the enterprise leaders in the society with strong inclination of uncertainty avoidance are more likely to formulate many regulations, and employees in that kind of society are better suited to different kinds of regulations[7].

\section{Statistical analysis on the differences in value orientations between Chinese and South Korean employees}

Data sources. The sample for this study consisted of 12 Sino-South Korean joint ventures in Dalian, which involved wholly Korean-owned, majority stake in South Korean side and majority stake in Chinese side. We released 282 questionnaires (Chinese versions) and received 272 questionnaires (Chinese versions). The response rate for the questionnaires (Chinese versions) in 12 Sino-South Korean joint ventures in Dalian was 96\%. Among these collected questionnaires (Chinese versions), a total of 261 usable responses were obtained. We also released 42 questionnaires (South Korean versions) and received 41 questionnaires (South Korean versions). The response rate for the questionnaires (South Korean versions) in 12 Sino-South Korean joint ventures in Dalian was 98\%. Among these collected questionnaires (South Korean versions), a total of 41 usable responses were obtained. The questionnaire only consisted of single choice questions. The basic information of the samples is shown in Table 1 and Table 2.

Table 1 The basic information of Chinese employees

\begin{tabular}{cccc}
\hline $\begin{array}{c}\text { Demographic } \\
\text { variable }\end{array}$ & Division & Number & Percentage (\%) \\
\hline Gender & Male & 199 & $76.25 \%$ \\
& Female & 62 & $23.75 \%$ \\
Age & Under 30 years old & 135 & $51.72 \%$ \\
& 31 to 40 years old & 92 & $35.25 \%$ \\
& 41 to 50 years old & 29 & $11.11 \%$ \\
& 51years and over & 5 & $1.92 \%$ \\
\hline
\end{tabular}

According to Table 1, because most of the samples are manufacturing enterprises, the percentage of Chinese male staffs is obviously higher than that of Chinese female staffs. And because of the low average age of the processing workers in manufacturing enterprises, the percentage of Chinese employees under 30 years old, and between 31 and 40 years old are much higher than that of remaining age cohort.

Table 2 The basic information of South Korean employees

\begin{tabular}{cccc}
\hline $\begin{array}{c}\text { Demographic } \\
\text { variable }\end{array}$ & Division & Number & Percentage (\%) \\
\hline Gender & Male & 36 & $87.80 \%$ \\
& Female & 5 & $12.20 \%$ \\
\hline \multirow{2}{*}{ Age } & Under 30 years & 4 & $9.76 \%$ \\
& old & 17 & $41.46 \%$ \\
& 31 to 40 years old & 15 & $36.59 \%$ \\
& 41 to 50 years old & 5 & $12.20 \%$ \\
\hline
\end{tabular}


According to Table 2, because majority of the South Korean employees in Sino-South Korean joint ventures are mid-level and high-level managers and they consider that middle and top management positions should be occupied by male staffs, the percentage of South Korean male staffs is obviously higher than that of South Korean female staffs. And because employees between 31 and 40 years old, and between 41 and 50 years old do their best work on the road, South Korean employees within those age cohorts play a pivotal role in middle and top management positions. That's why the percentages of South Korean employees within those age cohorts in Sino-South Korean joint ventures are obviously higher than those of remaining age cohorts.

Because of the limited number of South Korean employees in Sino-South Korean joint ventures, in most cases less than 10 Korean per enterprise, there is a wide gap between the number of Chinese and South Korean employees. But South Korea is a mono-ethnic state, which makes people's value orientations in South Korea highly similar. That's why the shortage of the limited number of South Korean employees in Sino-South Korean joint ventures may be made up to some extent.

Survey design and measurement approach.We used the value orientations included in Hofstede's cultural dimensions as the survey content, and used SPSS 17.0 and Excel 2003 for computing the score of the value orientations of Chinese and South Korean employees. Based on the scores, the differences in value orientations between the two sides are clear. 5-point Likert-type scale was used to measure the value orientations, and each choice represented a score ranging from 1(strongly disagree) to 5(strongly agree). The computation formula of score of value orientation is shown below:

Score of value orientation $=1 \times$ the percentage of "strongly disagree" choice $+2 \times$ the percentage of "disagree" choice $+3 \times$ the percentage of "neither agree or disagree" choice $+4 \times$ the percentage of "agree" choice $+5 \times$ the percentage of "strongly agree" choice

The differences in value orientations between Chinese and South Korean employees. According to Table 3, all the scores of value orientations of South Korean employees are higher than that of Chinese employees, except for the score of individualism.

Table 3 The difference in value orientations between Chinese and South Korean employees

\begin{tabular}{cccc}
\hline $\begin{array}{c}\text { Cultural } \\
\text { dimensions }\end{array}$ & Value orientation & $\begin{array}{c}\text { Score of South } \\
\text { Korean employees }\end{array}$ & $\begin{array}{c}\text { Score of Chinese } \\
\text { employees }\end{array}$ \\
\hline $\begin{array}{c}\text { Hofstede's cultural } \\
\text { dimensions }\end{array}$ & $\begin{array}{c}\text { Power distance } \\
\text { Individualism }\end{array}$ & 3.7317 & 3.6000 \\
& $\begin{array}{c}\text { Quality of life } \\
\text { Masculinity }\end{array}$ & 3.0244 & 3.0920 \\
& $\begin{array}{c}\text { Uncertainty } \\
\text { avoidance }\end{array}$ & 3.6585 & 3.5538 \\
& 3.6341 & 3.5402 \\
\hline
\end{tabular}

As shown in Table 3: (1) The South Korean employees express more support for unequal power distribution among people. This is because in traditional extended family in South Korea, fathers act as authority in the family and therefore are respected by all the family members. Further, the eldest sons act as the heir to family property and also possess authority in the family. The Chinese family members, however, have equal share of family property, and therefore father and elder son have limited authority[8]; (2) The South Korean employees have more dependence on the group. This is because of the collective characteristic of farming in South Korea and that encourages Korean to 
serve as a member of a group[9]. And the individual characteristic of farming in China encourages Chinese to be more independent; (3) The South Korean employees pay much more attention to deep communication. Firstly, this is because South Korean keep the extended family structure until early 1980's, which emphasizes on the family harmony. Chinese family, however, always keeps single monogamous family structure until Spring and Autumn and the Warring States Era[10]. As a result, South Korean has more profound sentiment for family members. Secondly, in terms of social communication, the "cultural revolution" in China makes Chinese indifferent to others, and therefore more and more people ignore others' troubles; (4) The South Korean employees are more inclined to favor the differences between gender roles. This is because women's status in China has improved significantly since May 4th Movement and founding of New China in 1949. Women's status in South Korea, however, is negatively influenced by the machismo in South Korean society; (5) The South Korean employees are more likely to deal with anxiety by minimizing uncertainty. This is because South Korean's anxiety is accumulated by shortage of natural resources and aggression from other nationalities in the history.

\section{Results}

Based on the results of the analysis of data from value orientation, and research findings on relationships between value orientations and behavior patterns, we obtained the following conclusions:

Firstly, most scores of the value orientations of South Korean employees are higher than those of Chinese employees (shown in Figure 1).

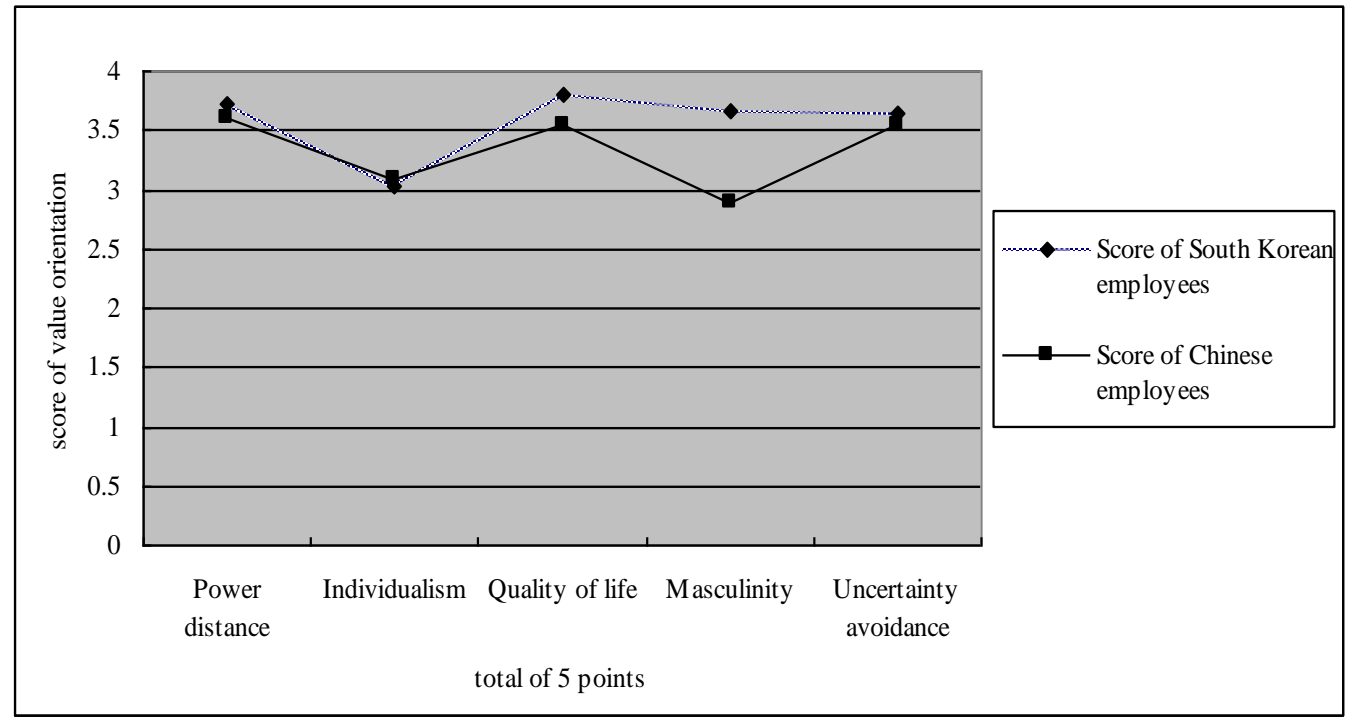

Figure. 1 The comparison between Chinese and South Korean employees

Secondly, with regards to Hofstede's research findings on the relationship between power distance and resulting behavior, it can be concluded that South Korean employees are more inclined to carry out instructions from superior.

Thirdly, with regards to Hofstede's research findings on the relationship between individualism-collectivism and resulting behavior, it can be concluded that South Korean employees have more sense of mission towards the enterprise.

Fourthly, with regards to Hofstede's research findings on the relationship between life quality and resulting behavior, it can be concluded that South Korean employees express more concern to employee welfare.

Fifthly, with regards to Hofstede's research findings on the relationship between masculinity and resulting behavior, it can be concluded that South Korean employees are more inclined to favor the 
differences between gender roles in the enterprise.

Sixthly, with regards to Hofstede's research findings on the relationship between uncertainty avoidance and resulting behavior, it can be concluded that South Korean employees are more inclined to accept different kind of enterprise regulations.

\section{Conclusions}

According to above analysis, we discovered the differences in behavior patterns between Chinese and South Korean employees. The plausible way to solve the differences is to promote local personnel. This solution, however, is not a short-term but a long-term approach.

According to the content of interview, we have known that middle and top management positions in Sino-South Korean joint ventures are mainly occupied by South Korean. The cross cultural conflicts between two sides can be explained in the following ways: firstly, some Chinese employees' behaviors do not come up to the norms of behavior of South Korean employees; secondly, the interests of some Chinese employees are affected by South Korean employees. It is therefore necessary to put forward some solutions to solve the problem in cross cultural management.

(1) According to the analysis on the differences in behavior pattern, the two sides are likely to come into conflicts in terms of execution capability. South Korean employees can carry out instructions from superior better. Chinese employees, however, would be rebuked by South Korean superiors because of limited execution capability. The rebuke from the South Korean superiors will make Chinese employees dissatisfied with them, and therefore make Chinese employees slack in work. This negative influence damages manufacturing enterprises particularly. To avoid such conflict, for some positions that is easily to cause accident, the enterprise leaders should educate employees in those positions by analyzing the causes and consequences of the accident resulted from limited execution capability.

(2) According to the analysis on the differences in behavior pattern, the two sides are likely to come into conflicts in terms of sense of mission towards the enterprise. To a larger extent, South Korean employees view the fate of enterprise as the foundation of personal development. Chinese employees, however, show more concern to the individual interest in the enterprise. According to the interview, we have known that some Chinese employees would have negative attitude to their own work because of the problems in career development. The South Korean superiors would believe that these Chinese employees lack positive attitude to work and dissatisfy with them. To avoid such conflicts, the enterprise leaders should formulate fair and comprehensive career planning and development. This is particularly important to Chinese employees who do their best work on the road because they are the core power for the development of enterprise.

(3) According to the analysis on the differences in behavior pattern, the two sides are likely to come into conflicts in terms of male-dominated enterprise. South Korean employees believe that middle and top management positions should be occupied by the male employees. Female employees, particularly some Chinese female employees, are therefore inclined to dissatisfy with South Korean employees. To avoid such conflicts, when South Korean superiors promote staffs, they should consider the reasonable composition of gender composition. Besides, Chinese female staffs with outstanding performance and leadership should be trained and promoted to middle and top management positions adequately.

(4) According to the analysis on the differences in behavior pattern, the two sides are likely to come into conflicts in terms of enterprise regulations. South Korean superiors are inclined to formulate different kinds of enterprise regulations, which will make Chinese employees difficult to adapt with and show resistances. To avoid such conflicts, South Korean superiors should consult the opinions of the Chinese employees when formulating regulations. As a result, the regulations will be approved by the most of the staffs. 


\section{References}

[1] Steel, P., \& Taras, V. (2010). Culture as a consequence: A multi-level multivariate meta-analysis of the effects of individual and country characteristics on work-related cultural values. Journal of International Management, 16(3), 211-233.

[2]Brockner, J., Chen, Y. R., Mannix, E. A., Leung, K., \& Skarlicki, D. P. (2000). Culture and procedural fairness: When the effects of what you do depend on how you do it. Administrative Science Quarterly, 45(1), 138-159.

[3]Fischer, R., Vauclair, C. M., Fontaine, J. R., \& Schwartz, S. H. (2010). Are individual-level and country-level value structures different? Testing Hofstede's legacy with the Schwartz Value [3]Survey. Journal of Cross-Cultural Psychology, 41(2), 135-151.

[4]Fang, T. (2010). Asian management research needs more self-confidence: Reflection on Hofstede (2007) and beyond. Asia Pacific Journal of Management, 27(1), 155-170.

[5]Yoo, B., Donthu, N., \& Lenartowicz, T. (2011). Measuring Hofstede's five dimensions of cultural values at the individual level: Development and validation of CVSCALE. Journal of International Consumer Marketing, 23(3-4), 193-210.

[6] Z, H, Wang. Cross-Cultural Management, Peking University Press, China,2009(in Chinese)

[7] Pat Joynt, Malcolm Warner. C, H, Lu, H, Y, Sun and J, Yang translated. Cross-Cultural Management, DongBei University of Finance Press, China, 2003.(in Chinese)

[8] X,R, Ding. Organizational culture comparison among Chinese, Korea and Japan: interpersonal trust-centered[J]. International Issues Forum, 2007, (48), p170-184(in Chinese)

[9] Q,Y, Jiang. The influencing factors of enterprise culture comparison between South Korea and Chinese[D]. Jilin University, China, 2007(in Chinese)

[10] L, H, Wang, G, G, Zhang. History of Chinese family. Guangdong People's Publishing House, 2007(in Chinese) 